method) allow reporting of sensitivity tests for mycobacteria to be available to users within days rather than weeks. It is no longer the case that it is necessary to wait the $8-10$ weeks described in the report.

Isoniazid resistance is only one of the resistances that are worrying in $M$ tuberculosis. The multiresistant strains that have been described recently are also resistant to other agents. The mechanisms for these are not well understood but may be due to factors other than gene deletion.

The mere detection of resistance to a single drug dose does not help in terms of predicting other sensitivity patterns or the interaction of combinations of antimycobacterial agents. It will remain essential for strains of $M$ tuberculosis and other mycobacteria to be sent to reference laboratories for identification and susceptibility testing, not only to guide the management of individual patients but equally importantly to provide the epidemiological information that will enable us to monitor national patterns of drug resistance in $M$ tuberculosis.

Thus, while representing an advance in our understanding, the description of this gene deletion will not offer any immediate and clear benefits to those concerned with the diagnosis and treatment of mycobacterial diseases.

B WATT

Scottish Mycobacteria Reference Laboratory,

City Hospital,

Edinburgh EH10 5SB

I Connor S. Gene deletion behind drug resistant tuberculosis. BM7 1992;305:441. (22 August.)

\section{Drug management of ulcerative colitis}

EDIToR,-Michael A Kamm and Asha Senapati provided an extensive review of drug management in ulcerative colitis.' We feel that one point is worthy of comment.

The authors erroneously state that mesalazine is 5-aminosalicylic acid coated with Eudragit-S. In fact mesalazine is the British approved name for 5 -aminosalicylic acid and is available in many different formulations including enteric coated tablets, sustained released tablets, rectal suppositories, and enemas.

There is little doubt that mesalazine preparations may rarely be associated with renal adverse effects, but the suggestion that "this may be related to the release and absorption of large amounts of unacetylated 5-aminosalicylic acid in the terminal ileum" is unfounded. Several authors have suggested that such events are probably due to hypersensitivity and are therefore independent of dose. ${ }^{3}$ Indeed, the mean serum concentrations of 5-aminosalicylic acid with different preparations are of the same order of magnitude.$^{5-8}$ For example, Dew et al quote a mean serum concentration of $(<0 \cdot 1$ to $0 \cdot 1 \mu \mathrm{g} / \mathrm{ml}$ for sulphasalazine compared with $0 \cdot 1 \mu \mathrm{g} / \mathrm{ml}$ with Asacol. ${ }^{8}$

Renal adverse effects have been seen in patients receiving many different preparations containing 5-aminosalicylic acid including oral and rectal mesalazine $^{2910}$ and oral sulphasalazine. ${ }^{410}$ This suggests that renal adverse effects are independent of the mechanism by which 5-aminosalicylic acid is released in the gut. ${ }^{5}$ There is also no available evidence to confirm the suggestion that unacetylated 5-aminosalicylic acid is more or less likely to cause renal effects than its acetylated metabolite.

Although the very small risk of renal adverse effects with the 5-aminosalicylic acid products should not be ignored, current evidence supports the suggestion that they are likely to be a "class effect" of 5-aminosalicylic acid and that dose, duration, and release mechanism may not have an important role in the development of such events. The proven efficacy of mesalazine in the manage- ment of ulcerative colitis far outweighs the small risk of idiosyncratic renal adverse events in those patients with no known renal impairment.

$S$ BARROW

SUSAN H REES

SmithKline Beecham Pharmaceuticals,

Welwyn Garden City,

Herts AL7 IEY

1 Kamm MA, Senapati A. Drug management of ulcerative colitis. BMY 1992;305:35-8. (4 July.)

2 Commitree on Safery of Medicines. Nephrotoxicity associated with mesalazine (Asacol). Current Problems 1990; No 30.

3 Swift GL, Mills CM, Rhodes J, Evans BK, Bennett A, Tavares IA. A pharmacokinetic study of sulphasalazine and two new formulations of mesalazine. Aliment Pharmacol Ther 1992;6 259-66.

4 Dwarakanath AD, Michael J, Allan RN. Sulphasalazine induced renal failure. Gut 1992;33:1006-7.

5 Choosing an oral 5-aminosalicylic acid preparation for ulcerative colitis. Drug Ther Bull 1992;30:50-2.

6 Christensen LA, Fallingborg J, Abildgaard K, Jacobsen BA, Sanchez G, Hansen SH, et al. Topical and svstemic availability of 5-aminosalicylate: comparison of three controlled release preparations. Aliment Pharmacol Ther 1990;4:523-33.

7 Laursen LS, Stokholm M, Buckhave K, Rask-Madsen J, Lacke Ke , Rask-Madsen J, Lauritsen K. Disposition of 5-aminosalicylic acid by olsalazine and three mesalazine preparations in patients with ulcerative colitis: comparison of intraluminal colonic concentration

Derumalues, and urinary excretion. Gut 1990,31:1271-6.

Cow , Ebden P, Kidwai NS, Lee G, Evan BK, Rhodes J. Comparison of the absorption and metabolism of sulphasalazine and acrylic-coated 5-aminosalicylic acid in normal subjects and patients with colitis. Br f Clin Pharmacol 1984;17:474-6.

9 Von Muhlendahl KE. Nephritis durch 5-aminosalicylsaure [Nephritis due to 5-aminosalicylic acid]. Dtsch Med Wochenschr 1989;114:236

10 Behrens R, Ruder H. Cronisch-entzundliche Darmerkrankung und Nephritis [Chronic inflammatory intestinal disease and nephritis]. Klin Padiatr 1992;204:61-4.

AUTHOR'S REPLY, - I welcome Dr Barrow's correspondence and additional information regarding the nephrotoxicity of 5-aminosalicylic acid drugs.

Although the mechanism may be one of hypersensitivity in some cases, it is not proved to be so in all. The fact that serum levels are similar for the different preparations of 5-aminosalicylic acid does not preclude the rare circumstance in which an individual absorbs an excessive amount of the drug in a short period of time. Now, however, the exact mechanism by which 5 -aminosalicylic acid causes nephrotoxicity must be regarded as inconclusive.

I accept that nephrotoxicity has been reported in association with a variety of 5-aminosalicylic acid preparations. I would completely agree that these drugs offer enormous benefit with only a very small risk. In practical terms these drugs can and should be prescribed for patients with ulcerative colitis.

St Mark's Hospital

MICHAEL A KAMM

\section{Selective serotonin reuptake inhibitors}

EDITOR,- In the debate in the correspondence on selective serotonin reuptake inhibitors, ${ }^{1.4} \mathrm{~T}$ Walley's summarisation of the key points made in our paper ${ }^{5}$ does not accurately reflect the substance of the argument which we outlined. We simply attempted to highlight the potential benefits which more widespread use of "non-tricyclic" antidepressant drugs would bring. It seems that Walley would dispute the efficacy and safety of "less established" drugs including the selective serotonin reuptake inhibitors. We are not aware of any convincing evidence that the older tricyclic drugs are more effective than the newer agents, but there can hardly be doubt that the older drugs are much more toxic both at therapeutic levels and in overdose. ${ }^{6}$

The issue of a possible legal challenge following death by suicide is an interesting one. There exists no published evidence that tricyclic drugs are more beneficial in preventing suicide, and they are frequently the agent of fatal self harm. ${ }^{*}$ A direct comparison of the influence of different categories of antidepressant drug on the epidemiology of suicide has not yet been made. We are currently collecting data which will provide some indication of the relative contribution of these drugs to all categories of suicide, not just the atypical group who die by overdose.

This is an important debate and we would urge all clinicians to look closely at the real costbenefit analysis. ${ }^{9}$ For depressed patients and their relatives the "newer" drugs (including the selective serotonin reuptake inhibitors) are a considerable advance in the treatment of depression.

Department of Mental Health,

KEITH MATTHEWS

University of Aberdeen,

Royal Cornhill Hospital,

Royal Cornhill Hospial

Ross Clinic,

JOHN M EAGLES

Royal Cornhill Hospital

Aberdeen AB9 2ZH

1 Edwards JG. Selective serotonin reuptake inhibitors. $B M \mathcal{Y}$ 1992;304:1644-6. (27 June.)

2 Harrison D. Selective serotonin reuptake inhibitors. $B M \mathcal{F}$ 1992;305:366. (8 August.)

3 Fradd SO. Selective serotonin reuptake inhibitors. BMF 1992; 305:366. (8 August.)

Walley T. Selective serotonin reuptake inhibitors. BMF 1992 305:526. (29 August.)

Matthews K, Eagles JM. Which antidepressant? Br f Gen Pract 1991:41:123-5

6 Cassidy S, Henry J. Fatal toxicity of antidepressant drugs in overdose. BMF 1987;295:1021-4.

7 Beaumont G. The toxicity of antidepressants. Br $\mathcal{F}$ Psychiatry 1989;154:454-8

8 Department of Health and Social Security. Health and personal service statistics for England. London: HMSO, 1985.

9 Matthews K, Eagles JM. Toxicity of antidepressants. Br f Psychiatry 1989;155:420.

\section{Misuse of temazepam}

EDIToR,-We write to support R Fox and colleagues' in calling for a withdrawal of all capsule formulations of temazepam and to provide evidence that such a withdrawal can be achieved without affecting clinical care of patients

In June 1991 the local medical committee, local pharmaceutical committee, and family health services authority covering the Sefton area agreed to recommend a voluntary switch from temazepam capsules to temazepam tablets to help combat the problems described by Fox et al.

A joint letter from the three organisations was sent to all general practitioners and community pharmacists. It explained the reasons for the proposed switch and sought cooperation from the practices, which were also asked generally to review their prescribing of all anxiolytic and hypnotic drugs. Mersey Regional Drug Information Service provided an information bulletin on the use of anxiolytic and hypnotic drugs. This was also circulated to all practitioners. Medical and Pharmaceutical Advisers from the family health services authority discussed the issue with practices on "improving prescribing" visits. We were also helped considerably by the fact that all hospitals in Merseyside had decided to switch to temazepam tablets during 1991.

During the quarter ending June 1991 in Sefton $3750000 \mathrm{mg}$ of temazepam were prescribed in capsule form and $3250000 \mathrm{mg}$ as tablets; in the quarter ending March 1992, $1300000 \mathrm{mg}$ were prescribed in capsule form and $3900000 \mathrm{mg}$ as tablets. Prescribing of elixir remained constant at $100000 \mathrm{mg}$. During the same period prescribing of all other hypnotics and anxiolytics, including newer agents, fell by $8 \%$.

Practices have reported very few problems and patients' acceptance of the change once an explanation has been given. Anecdotal evidence suggests that by June 1992 a further shift from capsules to tablets will have been achieved, and we now 